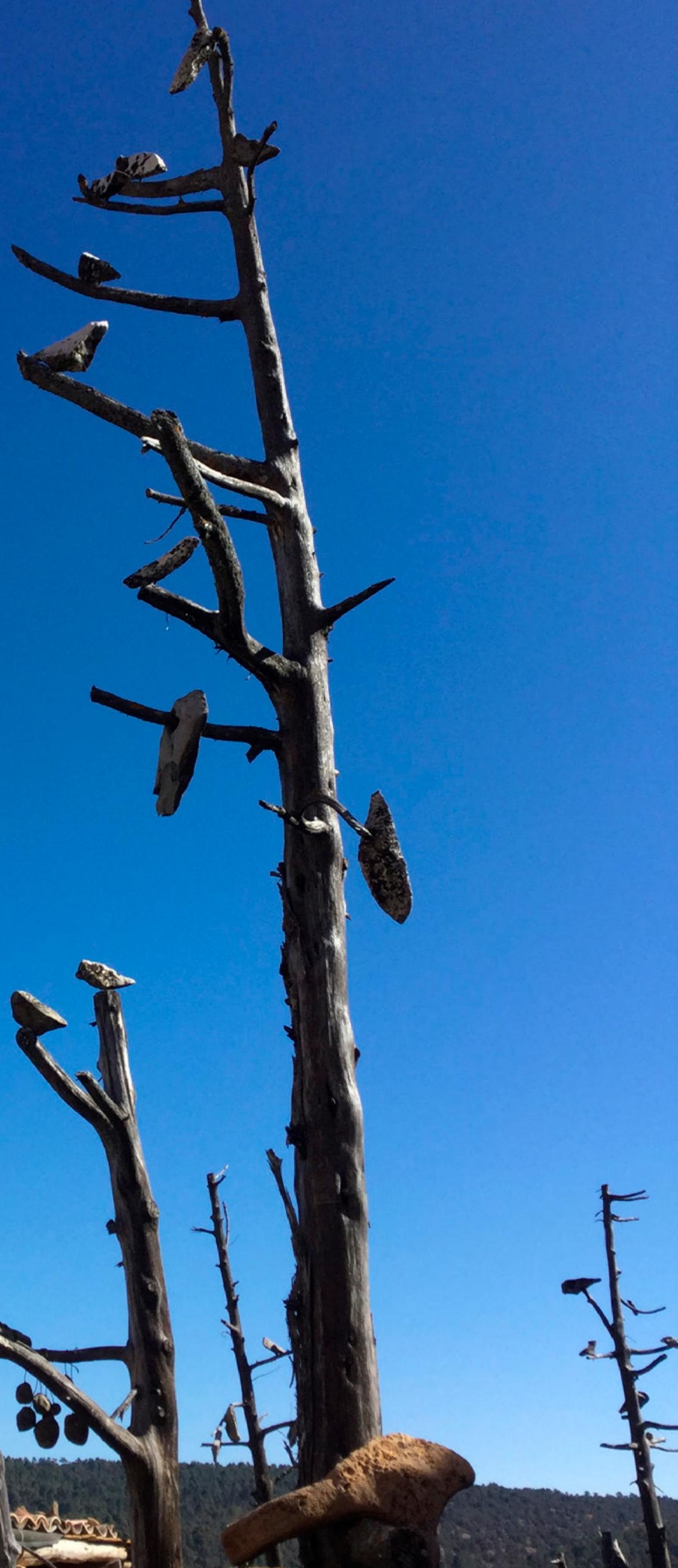




\title{
DIONISOS EN LA SERRANÍA. LOS ESPACIOS EXPOSITIVOS DE FERNANDO BUENACHE
}

\section{DIONYSUS IN THE MOUNTAINS. THE EXHIBITION SPACES OF FERNANDO BUENACHE}

\author{
Joan Manuel Marín \\ Universitat Jaume I de Castelló
}

Resumen

Palabras clave

Abstract

Keywords
En el presente artículo presentamos y analizamos la obra de Fernando Buenache a través de un recorrido por los tres sorprendentes espacios expositivos que el artista ha creado en su pueblo natal, Buenache de la Sierra: el Museo de Zoolitos, el Museo Etnobotánico; y el Parque de los Troncosaurios. Desde una perspectiva teórica, en las creaciones de Fernando Buenache se podrían descubrir muchos elementos del land art, los materiales y técnicas del arte povera y la fantasía del mundo surreal; incluso, en algunos momentos, el atrevimiento dadaísta. Sin embargo, por encima de todo ello, destaca la honestidad y la espontánea originalidad con las que este artista autodidacta realiza sus creaciones.

Land art, naturaleza, eco-arte, arte povera, Buenache de la Sierra, Cuenca.

In this article, we present and analyze the work of Fernando Buenache through a tour of the three surprising exhibition spaces that the artist has created in his hometown, Buenache de la Sierra: the Museum of Zoolitos, the Ethnobotanical Museum; and the Park of the Troncosaurios. From a theoretical perspective, many elements of land art might be discovered in Fernando Buenache's creations as well as materials and techniques from Arte Povera and the fantasy of the surreal world. A hint of Dadaist boldness might even be discerned at times. However, the honesty and spontaneous originality with which this self-taught artist endows his creations stands out above all this.

Land art, Nature, Eco-Art, Arte Povera, Buenache de la Sierra, Cuenca. 


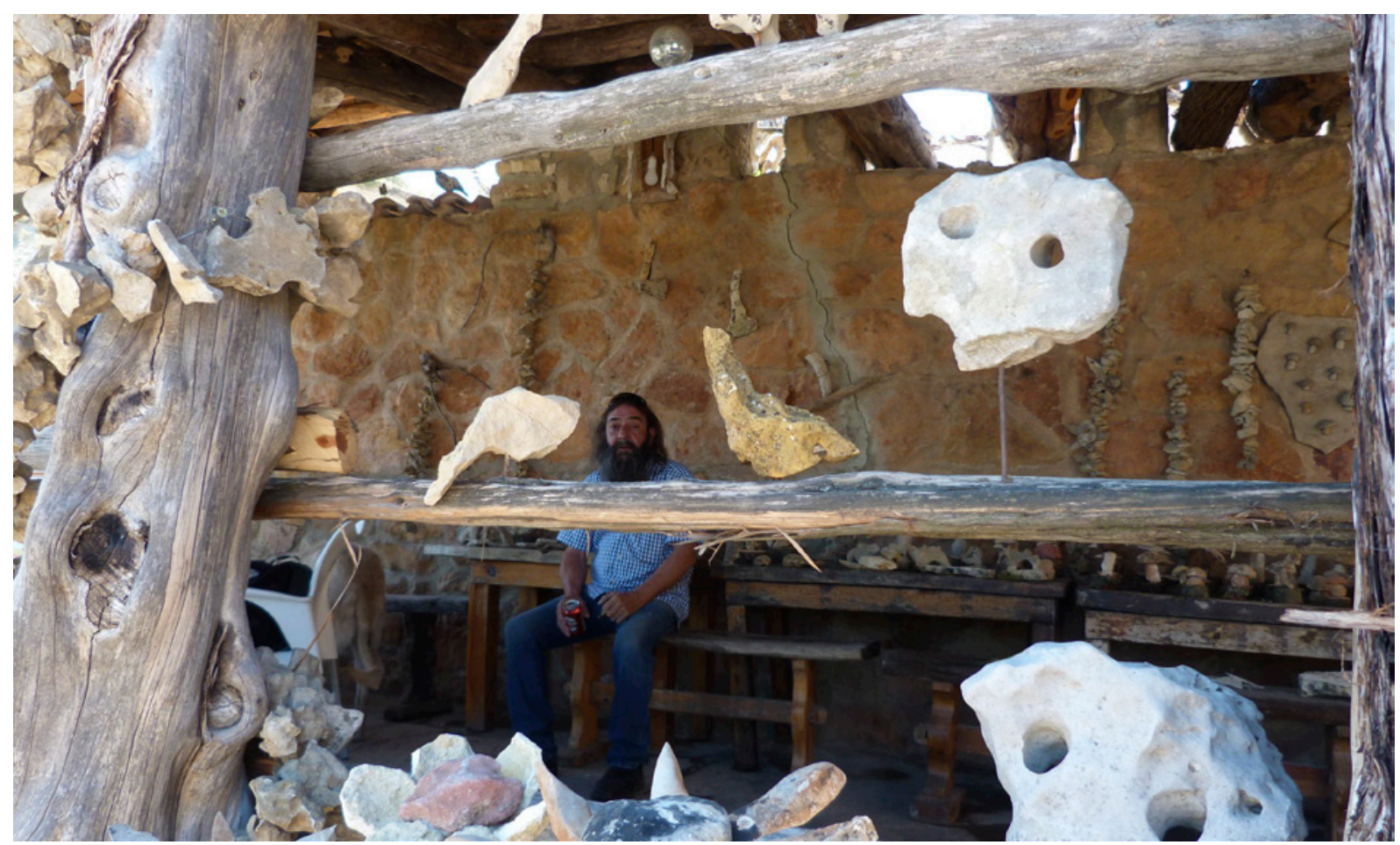

Mesón Las Pedrizas - Museo de Zoolitos.

Fui a los bosques porque quería vivir con un propósito; para hacer frente sólo a los hechos esenciales de la vida, por ver si era capaz de aprender lo que aquélla tuviera por enseñar, y por no descubrir, cuando llegase mi hora, que no había siquiera vivido.

(Henry David Thoreau, 2002: 93).

A 18 kilómetros al nordeste de Cuenca, situado a casi 1300 metros de altura, se encuentra Buenache de la Sierra. En este pequeño pueblo de la serranía conquense que en la actualidad apenas llega a sesenta habitantes -y a la mitad en invierno- se encuentran los tres singulares espacios expositivos creados por el artista Fernando Buenache. Se trata de tres propuestas que rompen con lo que, en palabras de Carmen Gracia, podría denominarse el «sistema artístico actual basado en la trilogía galeríacomisariado-crítica [que] mantiene al artista aislado de los verdaderos requerimientos de la sociedad» (2009: 52$)$

\section{Museo de Zoolitos}

\section{Hábitat 1: el mesón-museo...}

El primero de estos espacios, conocido como Museo de Zoolitos, está ubicado en el mesón Las Pedrizas, propiedad del mismo artista. A este asombroso mesón-museo se puede acceder desde la carretera por una escalera que asciende directamente a la zona exterior del conjunto expositivo, o también por la puerta del mesón que encontramos en una calle lateral. $\mathrm{Al}$ acceder por esta puerta, el visitante se ve sumergido de golpe en un mundo inesperado. Un hábitat en el que la luz amarillenta de las lámparas, construidas artesanalmente con cristales de espejuelo, iluminan los fantásticos seres de piedra que ascienden por las paredes y cuelgan de los techos.

Cuando a mediados de agosto de 2020 visitamos el lugar, el local había permanecido cerrado al público desde que, a mediados de 


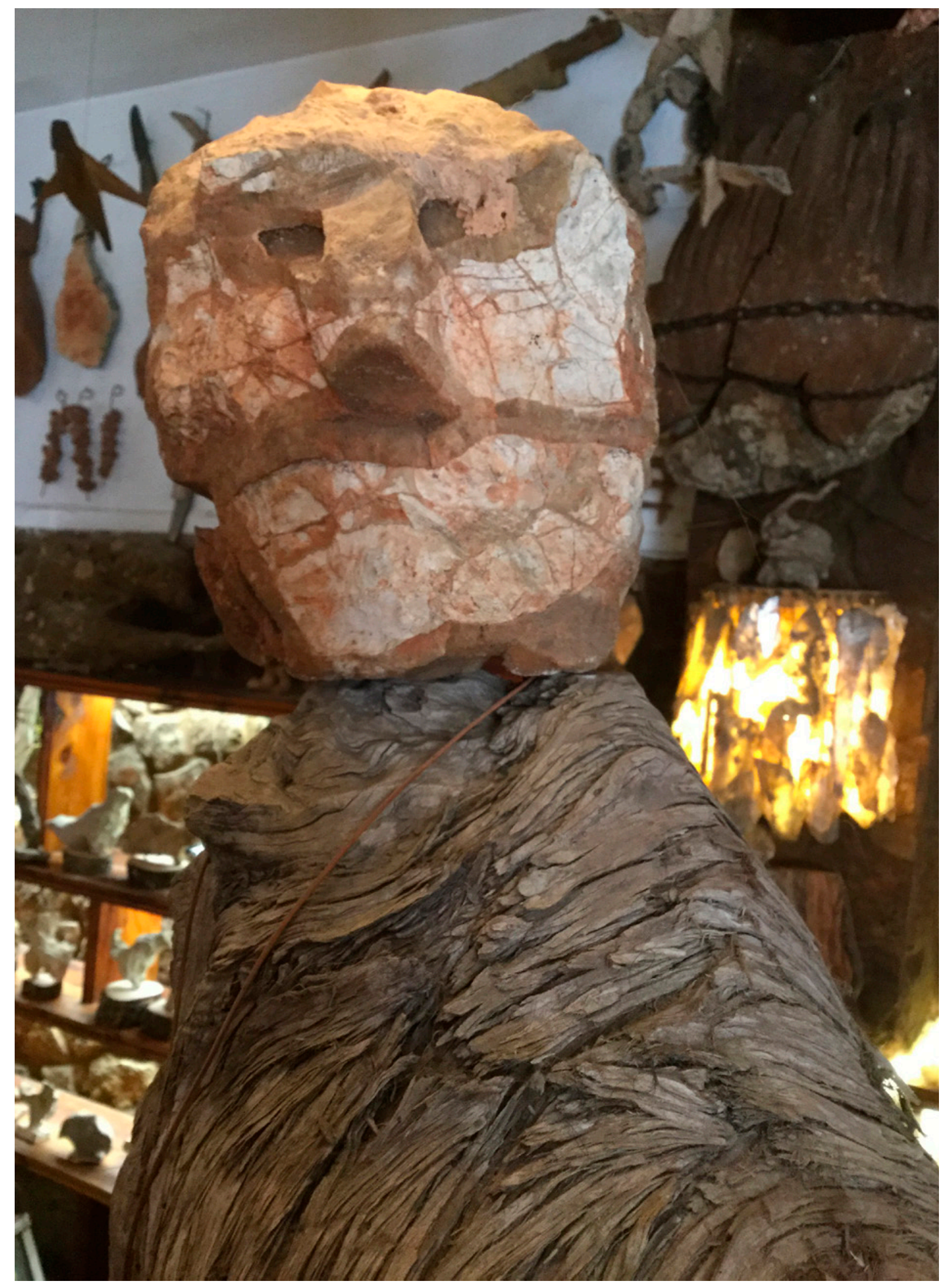

Mesón Las Pedrizas - Museo de Zoolitos. 


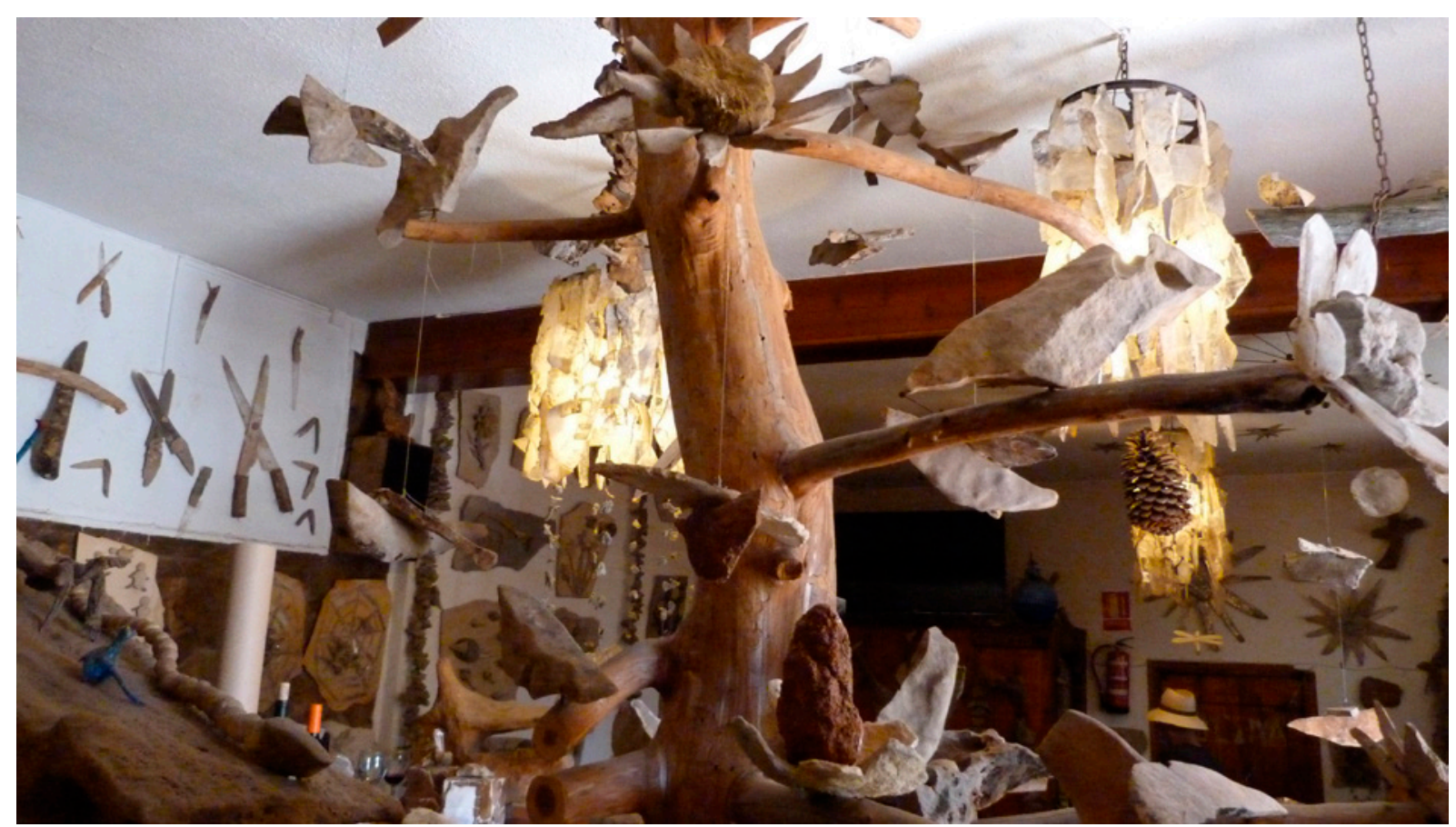

Mesón Las Pedrizas - Museo de Zoolitos.

marzo, comenzó la pandemia del coronavirus. Durante todo este tiempo, Fernando se sumergió en una continua actividad creadora de nuevas y fantásticas criaturas que se expandían por casi todas las mesas del restaurante. Más abigarrado y onírico que nunca, el espacio se nos aparecía en ese momento como la cueva en la que un resurgido Diógenes amontonaba sus tesoros líticos.

Etimológicamente, «zoolitos» vendría a significar animales de piedra, pero el local alberga una gran variedad de seres pétreos que van más allá de la fauna animal. Hongos surgidos de todos los bosques imaginables, extrañas plantas surgidas de la roca con sus tallos de hierro y cálices de piedra; y un sinfín de barrocas flores de guijarros comparten el espacio con troncos habitados por los más diversos animales: majestuosas libélulas de cristales de yeso, serpientes petrificadas en espirales inquietantes, tortugas, estrellas de mar, peces de especies desconocidas para su mismo creador, caracoles, armadillos, roedores y siluetas de aves incubando en sus nidos o perfiladas en todas las secuencias del vuelo.
Ninguna representación -trágica o cómicaparece faltar en este universo de piedra. Los homarraches recién salidos del mundo de los sueños y las decenas de fragmentos de roca alineados en los estantes parecen repasar las inagotables posibilidades expresivas del rostro humano. También encontramos una variada recreación de instrumentos musicales y, -cómo no, puesto que estamos en un mesón-museotampoco escasean las representaciones de utensilios y cubiertos de mesa (cucharas, tenedores, cuchillos), así como una extensa muestra de gastrolitos: jamones, embutidos, manitas de cerdo; y hasta pinchitos pedrunos. Lo trágico y lo cómico coexisten, pues bajo la mirada dionisíaca que preside el lugar nada se considera suficientemente elevado o banal como para desmerecer la existencia.

Por una puerta lateral del salón del mesón podemos salir a la terraza del local, situada en un montículo sobre el que Fernando Buenache ha erigido su particular jardín encantado. Desde aquí se puede observar a plena luz del día cómo sus esculturas de piedra han colonizado 


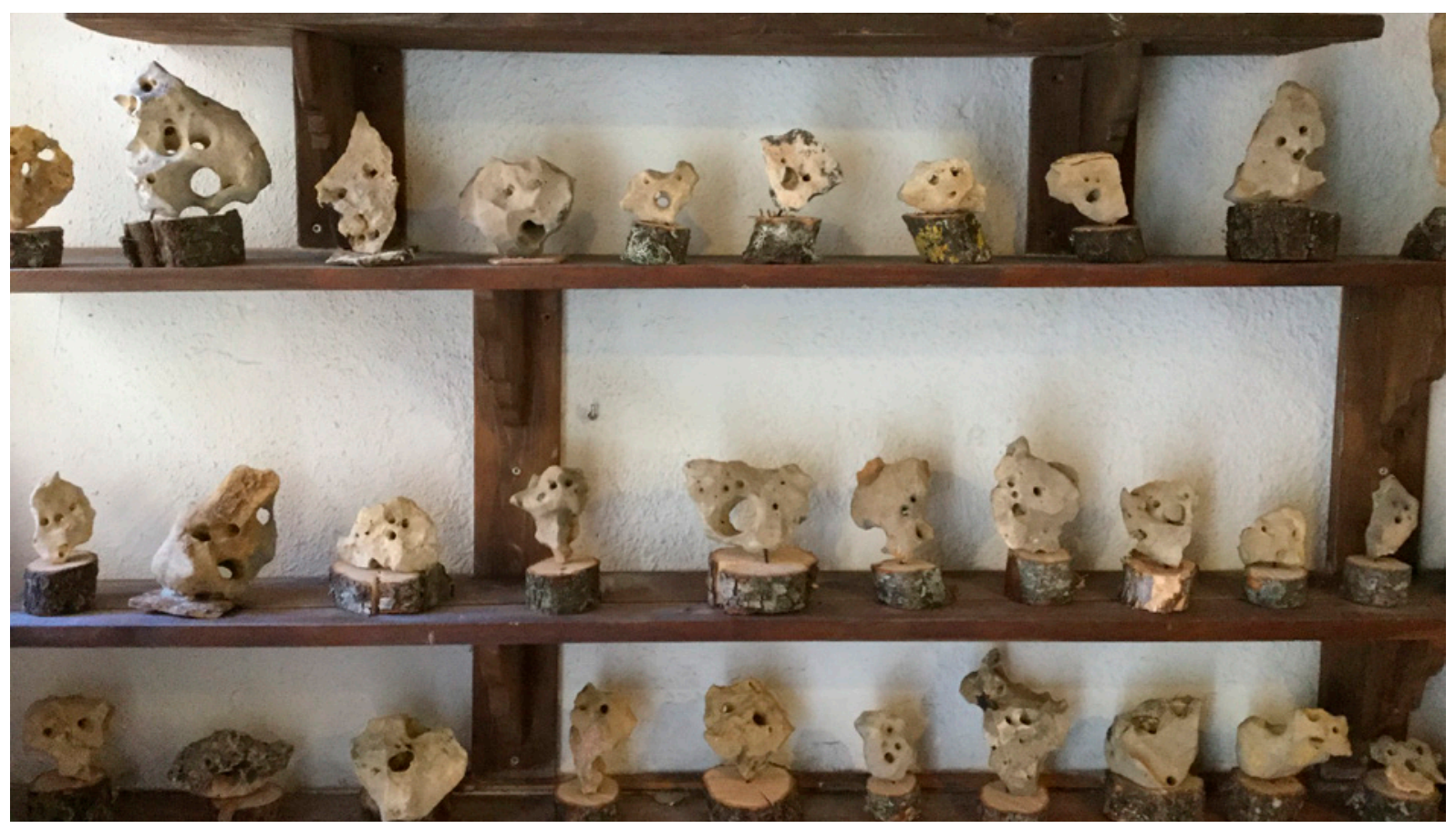

Mesón Las Pedrizas - Museo de Zoolitos.

por completo Las Pedrizas: las tortugas y las serpientes reptan por la pared de la fachada $y$ sobre las tejas se posan decenas de sus pájaros, mientras otros tantos revolotean bajo el techo de los cobertizos de madera. La sensación de irrealidad, provocada por el contraste de la madera desnuda y reseca con la frondosidad de las formas animadas, se adueña de este espacio exterior que está flanqueado por unas barandillas sobre las que se recuestan inquietantes troncos antropomórficos; parece un santuario en el que los restos de árboles adquieren formas totémicas y crecen flores de piedra.

Esta terraza exterior resulta también un excelente mirador desde el que se puede contemplar parte del pueblo, los campos colindantes y el Monumento a la Piedra que, a finales de 1989, levantaron Javier Floren, Marco Viola y el propio Fernando Buenache: una enorme roca que erigieron encima de un montículo tirando de ella con una trócola mientras se deslizaba sobre troncos de madera. Por último, en la planta superior del espacio de Las Pedrizas, también se encuentra el llamado
Museo Paleo-artístico: una colección de fósiles de unos 125 millones de años de edad geológica que combina el interés científico y el atractivo de su presentación plástica.

\section{El espíritu del caminante...}

Los espacios expositivos que nos ocupan son indisociables de la personalidad de su creador. Fernando Sánchez Buenache nació en 1960, en Buenache de la Sierra. Su segundo apellido muestra hasta qué punto está enraizado en su pueblo natal, un lugar en el que sus antepasados han vivido desde hace al menos seis siglos. Autodidacta de formación, Fernando trabajó desde joven en el campo, preferentemente en labores vinculadas con la madera. Durante su primera juventud su única relación con las piedras consistía en apartarlas de su camino cuando le molestaban, pero en 1987 su amistad con jóvenes artistas de la vanguardia conquense del momento -especialmente con Javier Floren y Marco Viola- le mostró una nueva forma de contemplar su entorno y le 
despertó su vocación artística. De esta época datan sus primeros zoolitos. Al principio -recuerda- los creaba para decorar el local, pero luego las creaciones fueron ganando en presencia e importancia y lo que era un medio se convirtió en un fin en sí mismo.

En el año 1992, una crisis personal lo llevó a dejar de lado el resto de sus ocupaciones y lo empujó al monte, agudizando su pasión por la búsqueda de piedras con las que realizar sus composiciones. Fernando se define principalmente como «muy paseante», lo más importante para su proceso creativo -nos dice- es "pasear mucho por la naturaleza, que está llena de tesoros». Al igual que sucede con otros muchos artistas del land art (Richard Long, Walter de Maria, Dennis Oppenheim, Robert Smithson, Hamish Fulton, o Miguel Ángel Blanco), las creaciones de Buenache son indisociables del acto de andar. Caminar es el acto primario que traza y fortalece los vínculos consigo mismo, con su obra y con su entorno. En una frase sobrecogedora, Fernando Castro Flórez (2015: 128) nos revela que «El hombre moderno ha pavimentado el mundo precisamente para que su pavor no sea visible». Tal vez por esto, en los años de su crisis, Fernando Buenache, se echó al monte; a caminar sin descanso sobre las sendas de tierra viva y de roca abierta para afrontar sus terrores particulares.

En una sociedad apresurada, que continuamente nos impone objetivos, caminar sin meta previa resulta un hábito bizarro, tanto en el sentido que este término tiene en español (valiente, arriesgado) como en el de sus acepciones francesa e inglesa (extravagante, raro). El monte es el lugar en el que el hombre rural se transforma en nómada; es la antesala de la transformación, cuyo útero es el bosque. La aldea, el pueblo y, con mayor precisión, la ciudad moderna, están diseñados para proporcionarnos la aparente sensación de seguridad que supone olvidarse de uno mismo. El monte y el bosque, en cambio, están ahí para que uno se pierda, se busque; y, tal vez, se encuentre. Como escribe Franco La Cecla:

Ya no somos capaces de otorgar un valor o un significado a la posibilidad de perdernos (...) En las culturas primitivas, por el contrario, si alguien no se pierde no se vuelve mayor. Y este recorrido tiene lugar en el campo. Los lugares se convierten en una especie de máquina a través de la cual se adquieren nuevos estados de conciencia (Franco La Cecla, cit. en Careri, 2002: 46).

Caminar por el campo, por el monte y por el bosque es un arte que requiere moldear el espíritu en la ascética de la soledad, y educar la mirada en la destreza de saber ver y reconocer las señales de la naturaleza. Desde niño Fernando Buenache sabía caminar por el monte, pero fue en estos años de crisis cuando aprendió a saber ver y descubrir las formas mágicas que se esconden en las piedras. El hombre de monte, ya de por sí observador, se convirtió en un buscador de figuras inesperadas; $y$, ante su mirada, el mundo se volvió panmórfico. Todo está lleno de formas: de las formas familiares que todos vemos y de las otras formas emboscadas que la mayoría no acertamos a ver. El joven Fernando Buenache, se perdió en el monte y regresó artista.

\section{El proceso creativo...}

Según nos confiesa Fernando, de sus inicios de caminante, a principios de los años noventa, data una revelación crucial que determinará su trayectoria: «la convicción de que la naturaleza es más maravillosa que cualquier cosa que yo podía hacer». Como artista de la tierra, Buenache utiliza los materiales que le proporciona el entorno, fundamentalmente la madera y la piedra. No en balde, junto a la ganadería, la saca de madera y las canteras de piedra han sido los principales sustentos de su pueblo desde su fundación, allá por el siglo XIII. También utiliza los cristales de yeso selénico, 


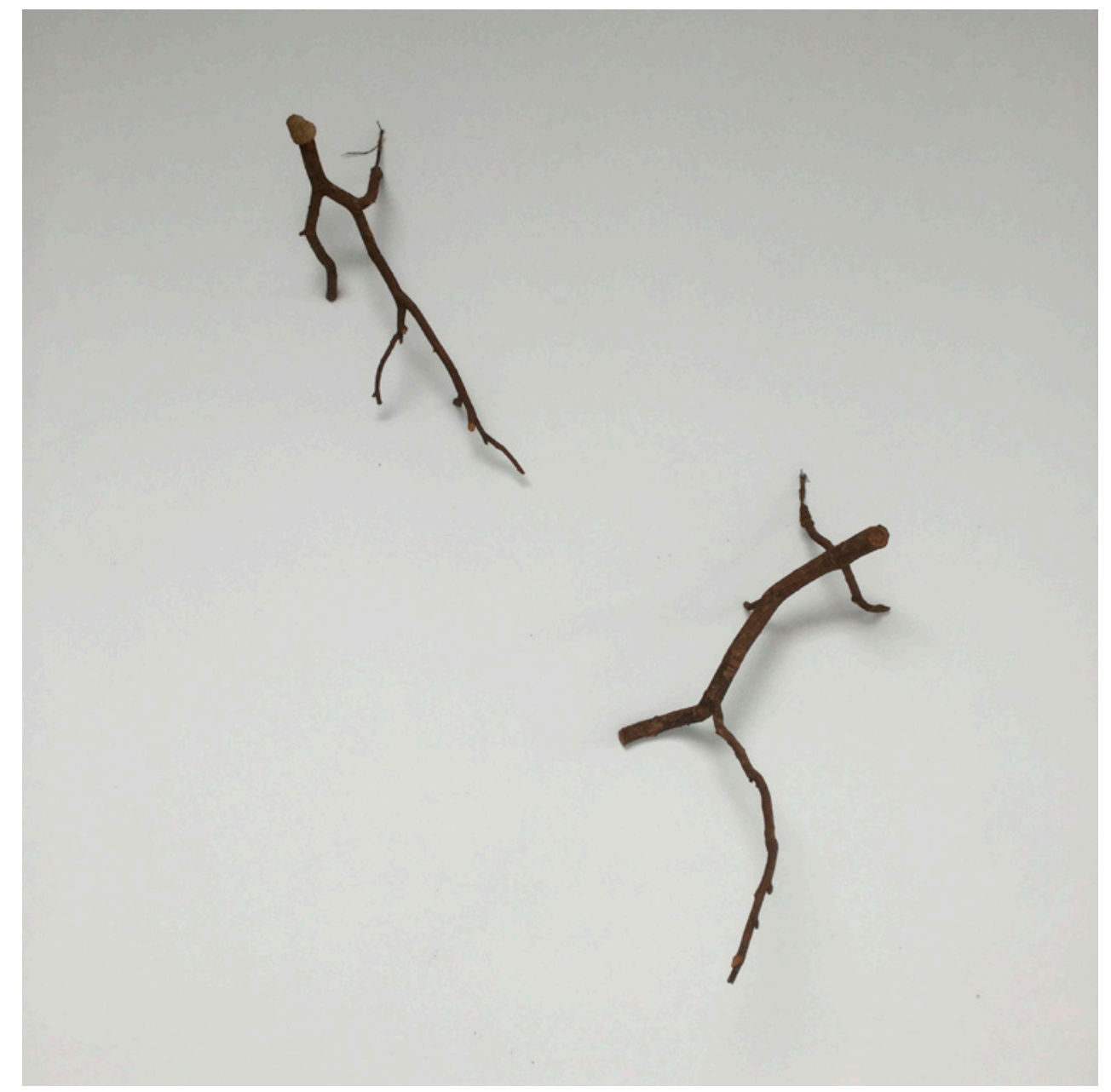

Mesón Las Pedrizas - Museo de Zoolitos.

el popular espejuelo (lapis specularis) que ya en tiempos del Imperio Romano se extraía de las minas de Segóbriga, situada en la actual provincia de Cuenca.

Como ya hemos avanzado, Buenache busca pacientemente en sus interminables paseos las piezas y fragmentos de los materiales que constituirán el fundamento de sus obras. No hay un patrón único $-\mathrm{y}$, mucho menos, fijo- que dirija la búsqueda. En algunas ocasiones sale al monte con una idea predeterminada de las formas deseadas; en otras es su mirada pareidólica la que descubre figuras insospechadas; y, las más de las veces, camina al azar, intuyendo que, como afirmó Fernando Castro Flórez: «Sólo el verdadero caminante es capaz de dejar que la ocasión le guíe, tomándose el tiempo necesario, esto es, distanciándose de cualquier pragmática, sabedor de que el deseo no tiene cartografía y que lo más importante es estar abierto a los encuentros» (2015: 153). Los hallazgos inesperados, quién sabe si debidos a la casualidad o a la predeterminación, constituyen la esencia de su obra, pues como podemos leer en el texto que José Luis Huerta escribió a propósito de la exposición de Fernando Buenache en el centro de arte La loma del Olvido del pintor Torrent: «Él piensa que encuentra, pero es la propia naturaleza quien los pone en su camino: cantos, piedras, ramas, madera, troncos, fósiles..., salen a su 
encuentro para que su mirada los transforme y les dé una segunda vida ${ }^{1} »$.

Después de estos encuentros, Buenache trata de reducir al mínimo la manipulación del elemento natural. El principio que guía su proceso creativo es no tallar. En sus creaciones se limita a dar al tronco de madera el equilibrio y la orientación que le proporcionará un nuevo sentido; a colocar sobre un pedestal con la inclinación adecuada la figura encontrada de piedra; o a unir los guijarros encontrados para crear nuevos seres y paisajes. En el texto para una de las exposiciones que Buenache realizó a mediados de los años noventa, Luis Muro ya subrayaba la parquedad de su técnica creativa:

En cuanto a su manera de hacer, hay que resaltar que su ascetismo técnico es el más acorde a sus fines, ya que la materia prima apenas sufre alteración alguna, pues con sólo cambiar de posición la piedra elegida y contraponerla a otra o unirla en diálogo a una raíz muerta de brezo o sabina, hace posible que una caliza en pétreo anonimato desde un remoto cretáceo, pueda ser diferenciada y admirada como flor, pájaro o serpiente².

Y veinte años después, tal como podemos constatar en las palabras con las que Tania Pardo, comisaria de la exposición «El curso natural de las $\cos ^{3}{ }^{3}$ », describía la poética de Buenache, este seguía fiel a su modo de proceder: «Buenache encuentra materiales en la naturaleza que posteriormente le son devueltos a ella sin manipular, transformados en diferentes composiciones que trasmiten una sensibilidad tan original como única» (Pardo, 2016: 101).

1 La exposición tuvo lugar en el centro de arte La loma del Olvido del pintor Torrent, durante los meses de agosto y septiembre de 2020, en Landete (Cuenca). El texto mencionado está disponible en red: <https://lomadelolvido.es/fernandobuenache-2020/> [Fecha de consulta 13/08/2020]

2 Texto de presentación de la exposición «Litos Buenache», que tuvo lugar en los Jardines de la Diputación Provincial de Cuenca del 14 al 30 de junio de 1996. El texto puede consultarse en red: <http://www.mesonlaspedrizas.com/index.php/ biografia $>$ [Fecha de consulta 12/08/2020]

3 Esta exposición colectiva tuvo lugar en La Casa Encendida de Madrid entre el 14 de octubre de 2016 y el 8 de enero de 2017.
El artista Perejaume, en su obra Natura $i$ Signatura (1990), quiso reflexionar sobre las complejas relaciones conceptuales que pueden establecerse entre naturaleza y arte yuxtaponiendo dos piedras idénticas: una piedra natural y anónima, que él mismo había escogido; y otra que, a imagen de la primera, el artista había esculpido y firmado. En las creaciones de Fernando Buenache, en cambio, no existe tensión conceptual entre arte y naturaleza, sino fusión simbiótica. Son creaciones que proceden tanto de la acción de los elementos naturales como del ingenio del artista; pertenecen a ambos por igual, tal vez por esto no están firmadas.

La obra de Fernando Buenache procede de una creatividad híbrida, no solo por la simbiosis entre arte y naturaleza que acabamos de mencionar, sino también por la mezcla que hay en ella de comportamientos propios del land art, reminiscencias del ready made dadaísta y técnicas artesanales propias del arte povera. Sin desdeñar, como nos recuerda Rosalía Torrent, cierto toque surrealista: «Su capacidad de detectar analogías entre lo animado y lo inanimado, y su evidente porte poético, le convierten en uno de esos creadores cuya originalidad entronca con el más puro surrealismo mágico, aliñado con la irreverencia de dadá ${ }^{4}$ ».

\section{Museo Etnobotánico}

A un par de calles del mesón-museo Las Pedrizas, se halla el segundo espacio expositivo, el denominado Museo Etnobotánico. Se trata de una vieja casa, en la que Buenache ha ido recogiendo antiguos utensilios, herramientas y aperos. El lugar podría visitarse como

\footnotetext{
4 Texto de la presentación de la exposición de Fernando Buenache en el centro de arte La loma del Olvido del pintor Torrent (Landete, Cuenca, 2020). Disponible en <https:// lomadelolvido.es/fernando-buenache-2020/> [Fecha de consulta 13/08/2020]
} 


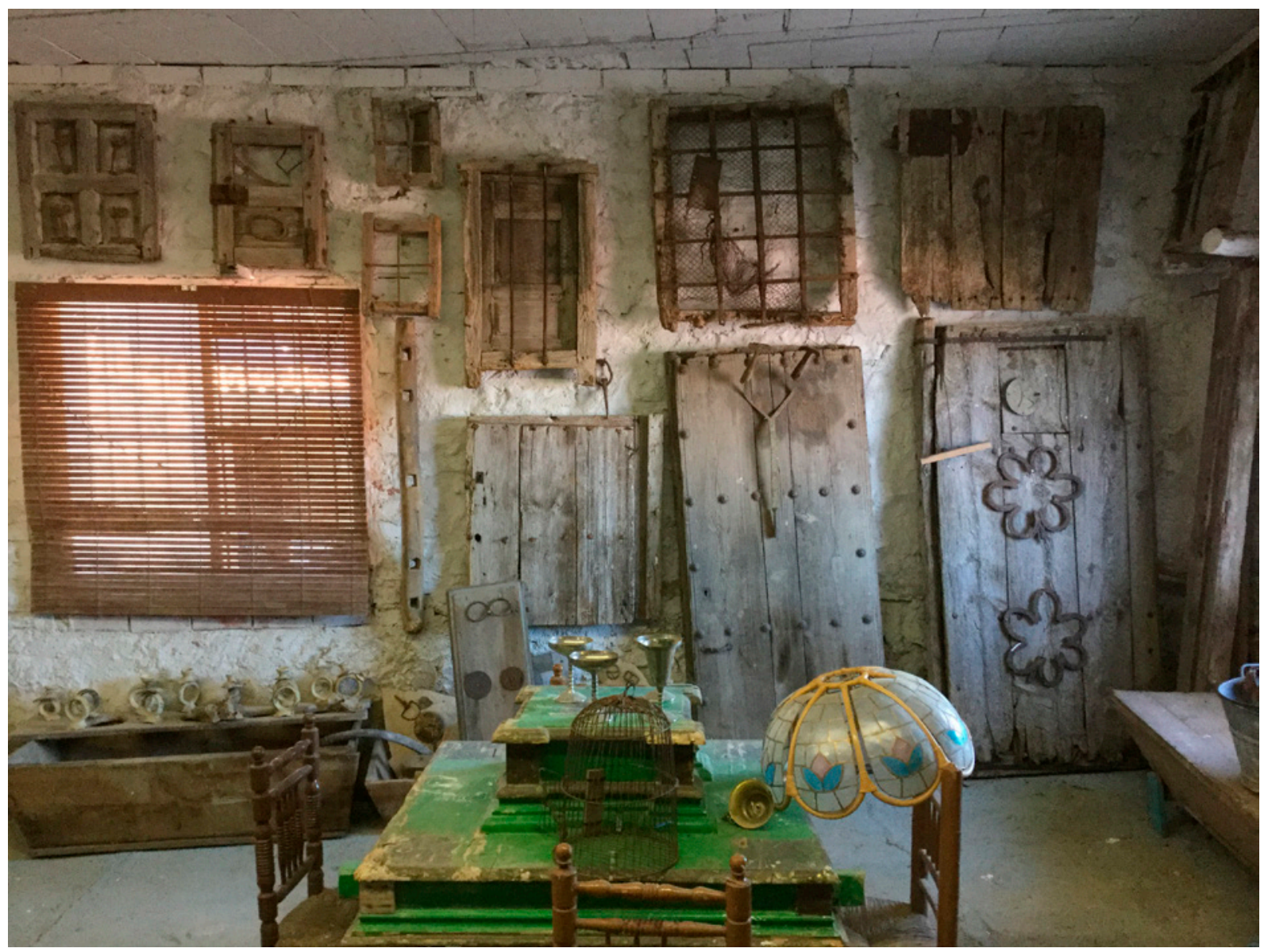

Museo Etnobotánico.

un pequeño museo etnológico, si no fuese porque la forma que tiene el artista de agrupar espacialmente los objetos crea unas composiciones de bella inspiración y austera factura, próximas al arte povera.

El arte povera, como en su día escribió Germano Celant, es «un himno al elemento banal y primario» (1985: 18). Los elementos utilizados en el arte povera son materiales baratos que han sido extraídos directamente de la naturaleza, cuando no son productos y enseres desechados de la vida cotidiana. La sensibilidad ante el entorno medioambiental sería el denominador común que conectaría al land art y al arte povera y les reuniría bajo el término de arte ecológico. En cierto sentido, como apunta Simón Marchán, el arte povera, "puede presentarse como una reacción al mundo tecnológico, con una cierta vena romántica» (Marchán, 1994: 215). La incesante renovación impuesta por el modo de vida contemporáneo arroja a los basureros del olvido montañas de objetos desahuciados. Desde que, en 1990, Fernando Buenache abrió este espacio, amplió su campo de búsqueda a los derribos y a las escombreras. Entre los restos que allí se amontonan, encuentra objetos que son fragmentos de vida pasada, jirones de la esencia de un tiempo que fue y que él recupera para la mirada actual. Estos objetos, como afirma Pascual Patuel sobre los elementos povera en su conjunto,

son pobres desde el punto de vista mercantil, pero muy ricos en significados, porque han sido utilizados desde el origen de la humanidad para 


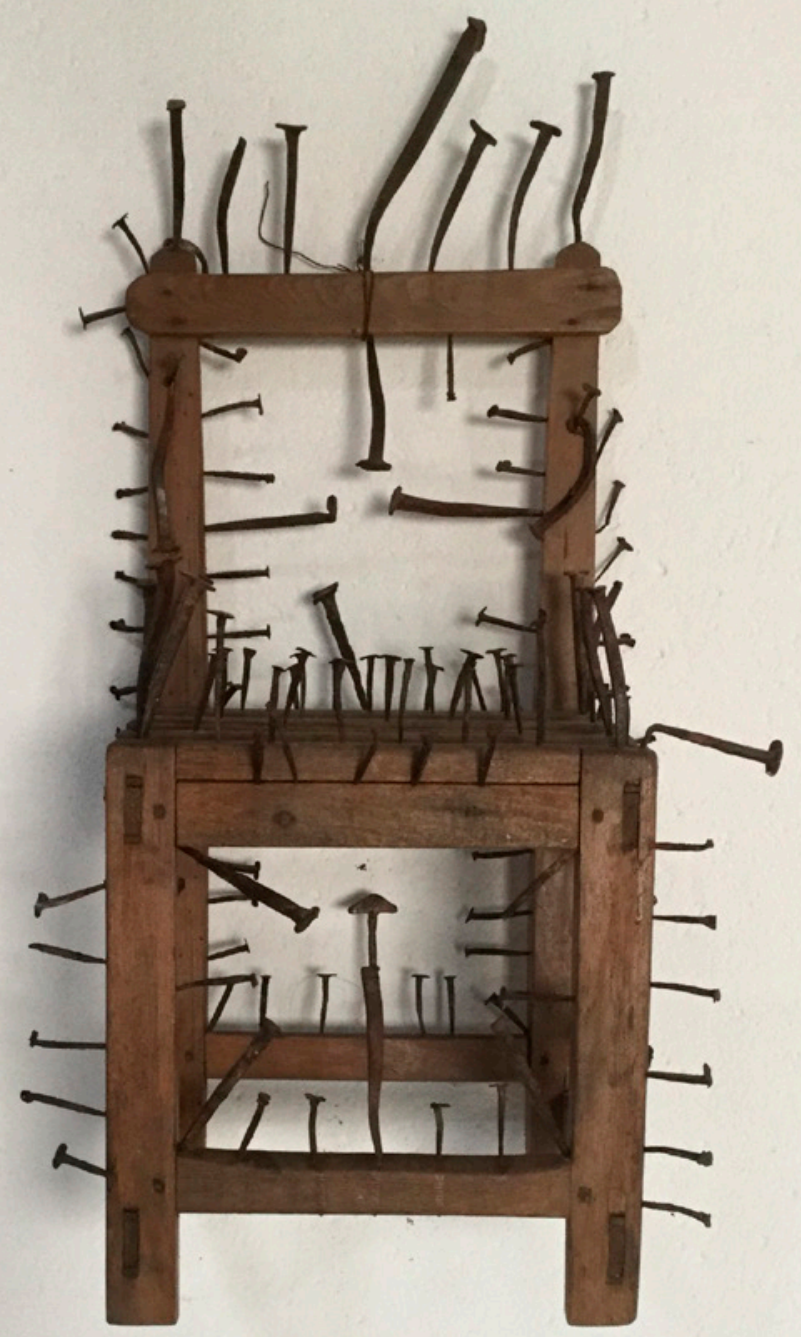


la supervivencia y, por tanto, conectan con nuestras raíces antropológicas (...) Por eso, cuando visualizamos una producción povera el contenido no es tanto lo que allí está presente cuanto las experiencias asociadas a los elementos mostrados (Patuel, 2016: 158).

En contraste con el mundo zoomórfico y onírico del Museo de Zoolitos, en el que la materia prima de la piedra y la madera van conformándose en figuras reconocibles, en este nuevo espacio, los restos de puertas y ventanas tienden a la abstracción que anida en el fragmento o el detalle; $y$ los variados utensilios expuestos pierden su individualidad, integrándose en la austeridad de la composición geométrica. Ciertamente, también se encuentran aquí objetos de una singularidad impactante como esa vieja silla de colegio -del colegio de su infancia- erizada con docenas de clavos. Otra obra híbrida que combina la intervención dadaísta en el objeto encontrado, el desgarro propio del expresionismo y los fantasmas del inconsciente surrealista. Pero, como hemos avanzado, en este espacio predomina la geometría. Estos fragmentos de puertas y ventanas son cápsulas del tiempo que, aunando la contundencia matérica y la perfección geométrica, revelan la poesía silenciosa $-y$, a menudo, inadvertidaque contiene la vida cotidiana. Reflejos materiales y transitorios de la eternidad de las ideas, son objetos nobles porque son antiguos, pero son antiguos porque son efímeros.

\section{Parque de los Troncosaurios}

Situado a un par de kilómetros del pueblo de Buenache de la Sierra, en la zona de Fuente Peñuela, encontramos el tercer espacio expositivo, el Parque de los Troncosaurios, con sus sorprendentes criaturas de madera. Se trata de una intervención en un extenso espacio al aire libre que reúne muchas de las características de una Ecovention $^{5}$, que, como explica Carmen Gracia,

5 Término creado por Amy Lipton que incluye los conceptos de ecología e invención.
... serían intervenciones o acciones realizadas en el contexto de un ecosistema. Sus componentes pueden ser visibles o invisibles, con un énfasis especial en los proyectos site-specific que implican llamada a la atención, recuperación, restauración, renovación y rejuvenecimiento de terrenos dañados o simplemente ignorados (Gracia, 2008: 53-54).

En 2009 a raíz del incendio de Alegonés, que arrasó 300 hectáreas de un bosque centenario de sabinas, Fernando Buenache empezó a recoger los restos de los árboles quemados. El árbol y el bosque son entes cargados de simbolismo que desde antiguo han adquirido una dimensión mágica o sagrada en múltiples culturas. El árbol, asentado sólidamente sobre la tierra, proporciona cobijo y alimento, regula las lluvias, purifica el aire y marca las estaciones del año. Como escribe Yáñez Velasco (2018: 3): «Parece un señor de la naturaleza que, al igual que ella, se adormece en invierno y despierta en primavera». Por su parte, el bosque es el útero frondoso de la tierra, representa la interioridad originaria que nos precede: «El bosque es un antes-yo, un antes-nosotros (...) el bosque reina en el antecedente» (Bachelard, 1998: 226).

Durante más de cinco años, Fernando Buenache estuvo seleccionando y acarreando los troncos de los árboles quemados al parque. Más de 1500. Una vez allí, mediante una mínima pero decisiva intervención -que, en la mayoría de las ocasiones, consistió en proporcionales el lugar, el equilibrio y la perspectiva adecuadalos troncos se transformaron en esculturas animadas.

La metamorfosis -bien lo sabe la crisálidaes una forma de escamotear la muerte; $y$, como escribe Calvo Serraller (2004: 8): «no hay un registro más amplio de configuración, y que haga más intensa y dramática su metamorfosis, como el de la madera». Buenache entra en el bosque después del fuego para redescubrir en los troncos quemados formas sorprendentes y gestos inesperados que les conferirán una nueva 


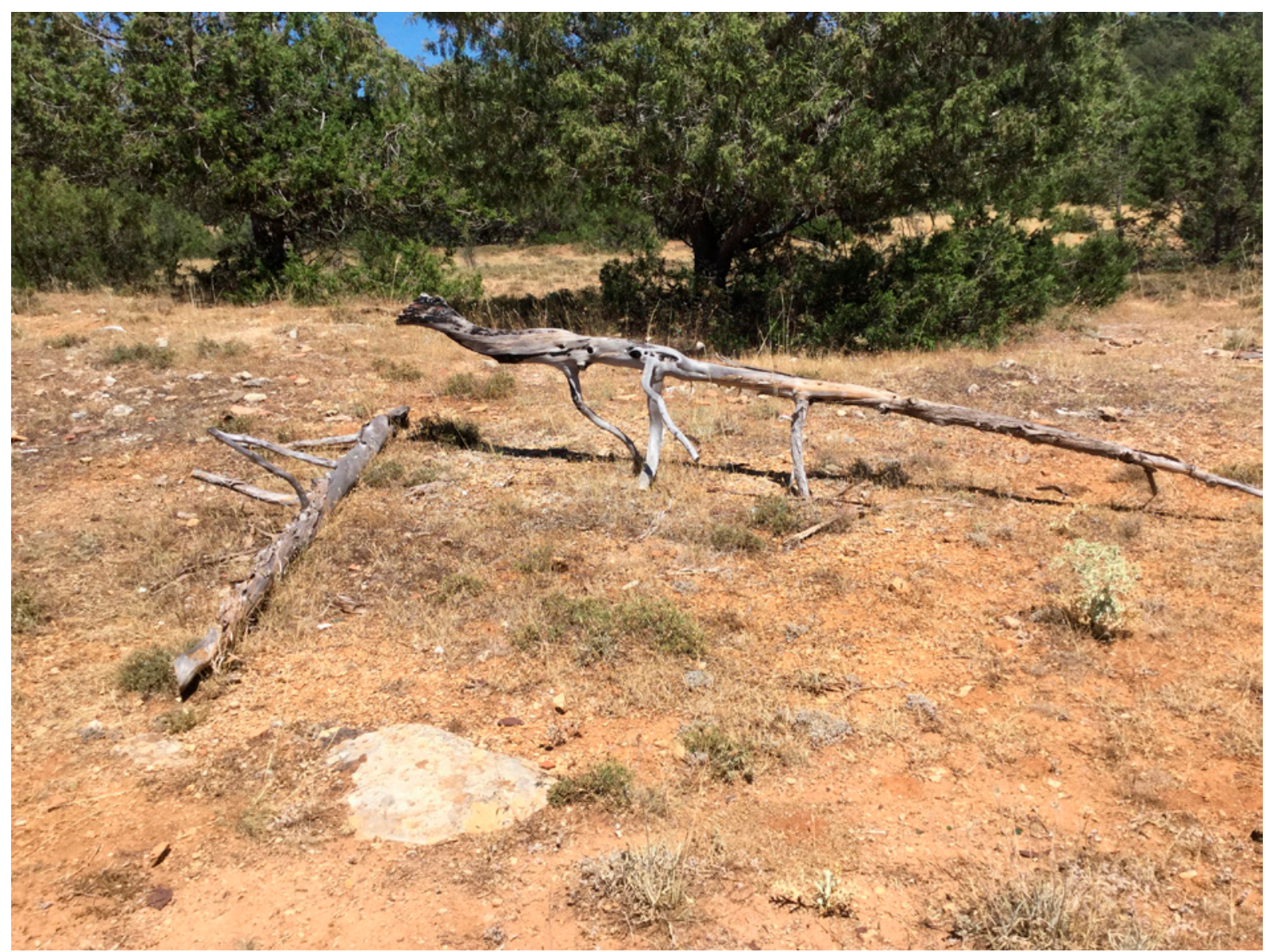

Parque de los Troncosaurios.

vida metamórfica. En un tronco quemado -podríamos pensar- siempre queda la sombra negra del dolor, pues un árbol quemado es un árbol torturado; de ahí el desgarrado expresionismo de algunas de estas obras talladas por el fuego. Pero estas esculturas también son árboles renacidos en forma de lagartos, dinosaurios, o troncos humanizados semejantes a los ents ${ }^{6}$, que celebran su nueva vida. Como nos relata Rosalía Torrent:

En un paraje de Buenache de la Sierra hay un bosque animado. Sus árboles ya no tienen raíces en la tierra, pero están vivos, y ahora se divierten bailando o conversando. Y pájaros de piedra se posan en sus ramas. Lo que antes fueron troncos

6 La especie de «pastores de árboles» que J. R. R. Tolkien creó para poblar la Tierra Media. devastados por fuegos e intemperies, ahora son figuras que atrapan la asombrada mirada de quienes visitan la zona ${ }^{7}$.

Al final del parque, detrás de una empalizada de madera, encontramos un recinto en el que Fernando amontona los troncos recogidos del incendio y que se adivina como el centro de operaciones del complejo. Es un espacio a medio hacer; un almacén de formas en el que las piedras esperan convertirse en caras; $y$ cientos de troncos aguardan el momento de su metamorfosis y un nuevo espacio en el que habitar. Pero también es un lugar en el que, poco a poco, Buenache va levantando una arquitectura mágica, con sus senderos jalonados con árboles

7 Ver nota 4. 


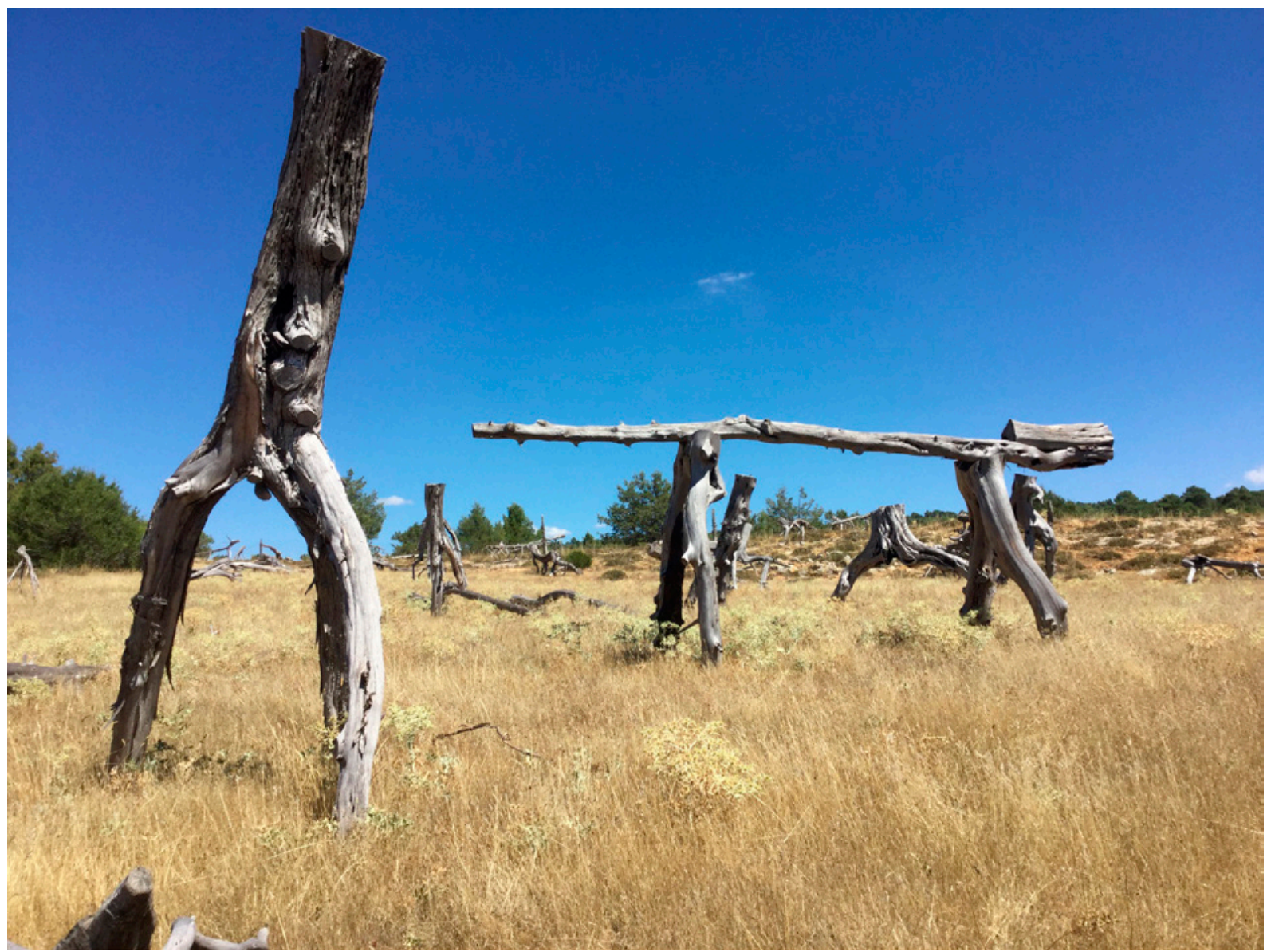

Parque de los Troncosaurios.

quemados que han recuperado la verticalidad y acogen las siluetas recortadas de los pájaros de piedra sobre el azul del cielo.

Aquí, el número y el tamaño de las obras se multiplica como podemos comprobar tanto en los zoolitos (serpientes, tortugas, rostros humanos) como en ese tronco retorcido que ha elegido transformarse en un gigantesco caracol. En diferentes espacios, acotados por piedras, las figuras se agrupan en cuadros escultóricos: en unas ocasiones parecen combatir troncosaurios y serpientes; $y$ en otras, los troncos vaciados por el tiempo y por el fuego se convierten en majestuosos tótems en los que, a modo de oasis oníricos, conviven una fantástica variedad de seres espectrales de piedra.

Desconcierta pensar que cada una de las composiciones escultóricas, que se cuentan por decenas en este parque, llenaría por sí sola la sala mayor de cualquier museo. Pero Buenache, el hombre del monte, el autodidacta, desconoce o menosprecia la lógica de la austeridad sobre la que se erige la opulencia de los mercados del arte; a saber, que la contención, la escasez, aumenta el precio. Su espíritu dionisiaco es tan excesivo, gratuito y efímero como la propia naturaleza («me resulta imposible saber cuántas piezas he compuesto», nos dice). Y Dionisos -ya se sabe- al contrario que Hermes, nunca fue un dios del comercio.

Por último, en el centro del recinto, alrededor de una gran sabina -la única que no está quemada - el artista ha trazado un círculo con rocas; y de los troncos de madera que lo circundan cuelgan las piezas de piedra que conforman un xilófono colectivo con el que reproducir la música del Neolítico. Ciertamente, en la obra de 


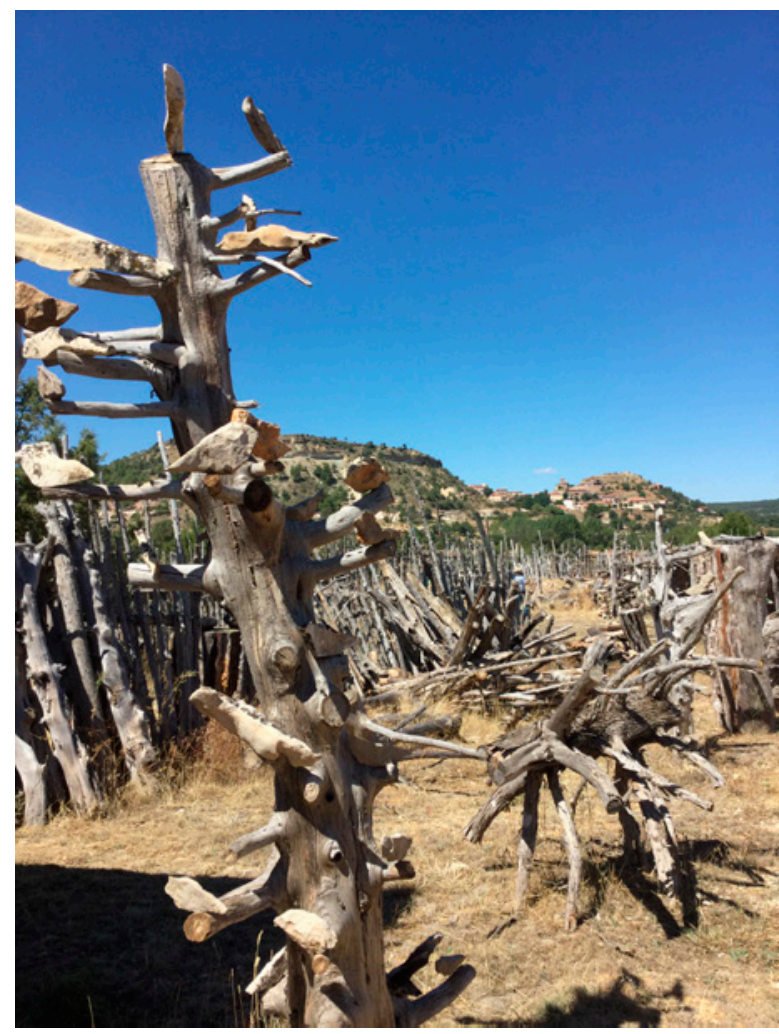

Parque de los Troncosaurios.

Buenache se aprecia una estética primitivista; un rasgo presente en muchas creaciones del land art, aunque se manifieste de formas muy diversas. Como nos recuerda Tonia Raquejo:

El land art surgió a finales de los sesenta bajo esta concepción de superposiciones periódicas. Así las «nuevas» formas ensayadas por artistas como Nichael Heizer, Nancy Holt, Robert Morris, James Pierce y Robert Smithson entre otros, en realidad parecen resurgir de la memoria prehistórica y de las civilizaciones primitivas (1994: 318).

Una de las mayores virtudes artísticas de Buenache consiste en descubrir y mostrar cómo el tiempo y los agentes naturales modelan la piedra y la madera. Las fuerzas que han tallado sus troncos y han esculpido sus caras son el agua, el aire y el fuego. No es de extrañar pues que sus obras conserven una esencia primordial y atávica, pues están conformadas por los cuatro principios primigenios.
Aunque no es fácil de olvidar obras como Effigy Tumuli (1983-1985), las cinco gigantescas figuras de animales (típula, pez, rana, tortuga y serpiente), creadas por Michael Heizer en el Buffalo Rock State Park de Ottawa, no abundan los artistas land que prefieran la figuración a la abstracción conceptual. Resulta notorio que gran parte de la producción del arte contemporáneo se caracteriza por su difícil comprensión: poco -o «nada» según Adorno (1980: 9)- resulta en él evidente; y Jean Baudrillard fue más rotundo todavía al afirmar, tras visitar la Bienal de Venecia de 1993, que el arte se había convertido en "un complot e incluso un "delito de iniciados"» (Baudrillard, 2006: 119). Sin embargo, también hay artistas que crean a contracorriente. Buenache es uno de ellos; comenzó buscando formas abstractas y luego pasó a la figuración. Cuando le preguntamos el porqué de esta transición que en muchos otros suele ir en sentido contrario, su respuesta resultó reveladora: «... porque las formas abstractas puede que solo las vea yo; y las figuras las reconoce la gente». Fernando Buenache es un solitario, pero no tiene el comportamiento solipsista que ha llenado de incomprensión y de ansiedad gran parte del arte contemporáneo. Ancestral pero lúdica, su figuración mágica, en ocasiones inquietante y en ocasiones naif, no tiene ningún reparo en apostar a las claras por los principios de familiaridad y de participación que están en la base del gusto popular. Es el modo y el medio que tiene este artista -ajeno a cualquier servidumbre de los circuitos artísticos-de asegurar su vínculo y su compromiso con la gente.

\section{Dionisos en la serranía...}

En el Parque de los Troncosaurios se evidencia el espíritu dionisiaco que ya mencionamos al hablar del Museo de Zoolitos. Dionisos -conocido entre los romanos con el nombre de Baco- es un dios de la vegetación, de los bosques y de la fauna salvaje. Su muerte, 
despedazado por los titanes, y su posterior renacimiento anual simbolizan los ciclos de la naturaleza. Los troncos animados y los animales de piedra de Fernando Buenache pertenecen a los dominios de Dionisos, cuyo ímpetu transgresor no admite compartimentos estancos, salta de un género a otro, fusiona las especies y unifica los reinos de la naturaleza. Al igual que el dios patrón de la tragedia y de las bacanales, sus caras y sus homarraches participan de la celebración y del desgarro; pues lo mismo observan, espantadas, el lado terrible de la existencia, que contemplan festivas el baile de los árboles renacidos. En sus rostros de piedra asoma tanto la sonrisa burlona como el espanto.

A diferencia de la sobriedad de la poética que dirige la obra de la mayoría de los artistas land (pensemos en Robert Smithson, Richard Long, Dennis Oppenheim... y tantos otros), llevándoles a encerrar el significado de sus obras dentro de contención de las figuras geométricas más simples, la creatividad de Buenache se desborda en una incontenible figuración en la que, como en el torrente de la vida, casi todo tiene cabida. Su obra multiplica tanto la variedad como la repetición, configurando un espacio fantásticamente abigarrado el que conviven, sin ninguna jerarquía excluyente, lo esencial y lo trivial, el hallazgo original y las fruslerías. Son los dominios de Dionisos, instintivo y siempre excesivo, que todo lo celebra y equipara.

¡Evohé! ¡Evohé!... Parecen cantar sus figuras en el monte durante las noches de viento:

Manifiéstate como un toro o como multicéfala serpiente o como león de aspecto llameante.

Ven, Baco, y al cazador de bacantes, tú, con rostro sonriente, échale el lazo mortal, porque irrumpió en el tropel de las ménades ${ }^{8}$.

8 Eurípides, Bacantes, vv. 1017-1023. La traducción castellana es de Dionisio Mínguez Fernández. Cit. en Colli, 1995: 63.

\section{REFERENCIAS Y BibLIOGRAFíA}

Adorno, Theodor W. (1978) Teoría estética, Madrid: Taurus.

BACHelard, Gaston (1998) La poética del espacio, México: Fondo de cultura Económica.

Calvo Serraller, Francisco (2004) «Remontar el tiempo», David Nash, Madrid: Galería Metta.

CARERI, Francesco (2002) Walkscapes. El andar como práctica estética, Barcelona: Gustavo Gili.

Castro Flórez, Fernando (2015) Mierda y catástrofe, Madrid: Fórcola.

Celant, Germano (1985) «1968. Un arte povera, un arte crítico, un arte iconoclasta. 1985», Del arte povera a 1985, Madrid: Dirección general de Bellas Artes.

Colli, Giorgio (1995) La sabiduría griega (tomo I), Madrid: Trotta.

GrACIA, Carmen (2008) «El reencantamiento de la naturaleza: una aproximación al Eco-Arte», $C B N, 0: 48-57$.

MARChÁn Fiz, Simón (1994) Del arte objetual al arte del concepto. Epílogo sobre la sensibilidad «postmoderna», Madrid: Akal.

PAtuel, Pascual (2016) Arte actual, Valencia: Universitat de València.

PARdo, Tania (coord.) (2016) El curso natural de las cosas, Madrid: La Casa Encendida.

RAQUEJO, Tonia (1994) «El land art como metáfora de la historia», El papel y la función del arte en el siglo $\mathrm{xx}$, Bilbao: Universidad del País Vasco.

- (1998) Land art, San Sebastián: Nerea.

Thoreau, Henry David (2002) Walden o la vida en los bosques, Barcelona: Los libros de la frontera.

YÁÑEZ Velasco, Marcos (2018) «Simbología y culto del árbol y el bosque en los inicios de la cultura europea», Boletín Carpeta informativa del CENEAM. Disponible en https://www.miteco.gob.es/es/ceneam/articulos-de-opinion/2018-06-marcos-yanez_tcm30450488.pdf [Fecha de consulta 20/08/2020]

Recibido el 9 del 9 de 2020

Aceptado el 8 del 10 de 2020

BIBLID [2530-1330 (2020): 94-109] 